\title{
Pullulan Acetate Coated Magnetite Nanoparticles for Hyper- Thermia: Preparation, Characterization and In Vitro Experiments
}

\author{
Fuping Gao ${ }^{1}(\varangle)$, Yuanyuan Cai ${ }^{1,2}$, Jing Zhou ${ }^{1,2}$, Xiaoxue Xie ${ }^{1,3}$, Weiwei Ouyang ${ }^{1,3}$, Yuhui Zhang ${ }^{1,2}$, Xufei Wang ${ }^{1}$, \\ Xiaodong Zhang ${ }^{1}$, Xiaowen Wang ${ }^{1}$, Lingyun Zhao ${ }^{1}$, and Jintian Tang ${ }^{1}(\varangle)$ \\ ${ }^{1}$ Key Laboratory of Particle \& Radiation Imaging, Ministry of Education, Institute of Medical Physics and Engineering, Department of \\ Engineering Physics, Tsinghua University, Beijing 100084, China \\ ${ }^{2}$ Department of Biopharmaceutics, Beijing University of Traditional Chinese Medicine, Beijing 100102, China \\ ${ }^{3}$ Department of Oncology, Xiangya Hospital of Central South University, Changsha 410008, China \\ Received: 24 September 2009 / Revised: 16 November 2009 / Accepted: 18 November 2009 \\ (C) The Author(s) 2010. This article is published with open access at Springerlink.com
}

\begin{abstract}
Amphipathic polymer pullulan acetate (PA)-coated magnetic nanoparticles were prepared and characterized by various physicochemical means. The cytotoxicity and cellular uptake of the magnetic nanoparticles were examined. The hyperthermic effect of the magnetic nanoparticles on tumor cells was evaluated. Transmission electron microscopy (TEM) showed that the PA coated magnetic nanoparticles (PAMNs) had spherical morphology. Dynamic light scattering (DLS) showed that the size distribution of PAMNs was unimodal,with an average diameter of $25.8 \mathrm{~nm} \pm 6.1 \mathrm{~nm}$. The presence of the adsorbed layer of PA on the magnetite surface was confirmed by Fourier transform infrared (FTIR) spectroscopy. Magnetic measurements revealed that the saturation magnetization of the PAMNs reached $51.9 \mathrm{emu} / \mathrm{g}$ and the nanoparticles were superparamagnetic. Thermogravimetric analysis (TGA) showed that the $\mathrm{Fe}_{3} \mathrm{O}_{4}$ particles constituted $75 \mathrm{wt} \%$ of the PAMNs. The PAMNs had good heating properties in an alternating magnetic field. Cytotoxicity assay showed that PAMNs exhibited no significant cytotoxicity against L929 cells. TEM results showed that a large number of PAMNs were internalized into KB cells. PAMNs have good hyperthermia effect on KB cells in vitro by magnetic field induced hyperthermia. These novel magnetic nanoparticles have great potential as magnetic hyperthermia mediators.
\end{abstract}

\section{KEYWORDS}

Magnetic nanoparticles, pullulan acetate,hyperthermia, cytotoxicity, cellular uptake

\section{Introduction}

Magnetic nanoparticles with tailored surface chemistry have recently attracted a great deal of attention by virtue of their potential biomedical applications including magnetic resonance imaging (MRI) contrast enhancement [1-4], hyperthermia [5-7], immunoassay [8], and drug delivery [9]. Hyperthermia involves applying an alternating magnetic field of suitable frequency that produces heat dissipation through the oscillation of the internal magnetic moment of superparamagnetic particles. Hyperthermia using magnetic nanoparticles either alone, or in association with classical chemo- or radiotherapies, has been recognized as a useful therapeutic modality in the treatment of malignant tumors $[10,11]$ because the

Address correspondence to Jintian Tang, tangjt@mail.tsinghua.edu.cn; Fuping Gao, gaofp158@gmail.com

\section{基 Springer}


neoplastic cells are more thermosensitive than normal cells [12]. For hyperthermic applications, nanomagnetic particles should have high magnetization values in order to generate high thermal energies and size smaller than $50 \mathrm{~nm}$ with a narrow particle size distribution. In addition, hyperthermic thermoseeds require a surface coating of the core magnetic particles, which has to be not only nontoxic and biocompatible but also gives targetable particles with particle localization in a specific area. Because of their hydrophobic surfaces and large surface area to volume ratio, in vivo use of nano-magnetic particles trends to result in agglomeration and very rapid clearance from the circulation. In addition, a common problem of uncoated magnetic nanoparticles is their chemical instability with respect to oxidation in air [13]. In the case of iron oxides, the final compositions are very often intermediate between magnetite $\left(\mathrm{Fe}_{3} \mathrm{O}_{4}\right)$ and maghemite $\left(\gamma-\mathrm{Fe}_{2} \mathrm{O}_{3}\right)$, due to oxidation of the particles during the synthesis [14]. Surface modification or coating of iron oxide nanoparticles with biocompatible polymers is often indispensable for in vivo biomedical applications in addition to prevent oxidation of the particles.
Pullulan is a flexible water soluble, neutral linear polysaccharide consisting of $\alpha-1,6$ linked maltotriose residues (Fig. 1(a)) which is used extensively as a food additive, and has therefore been shown to be safe for human use. However, recently pullulan has also been investigated for its biomedical applications in areas such as targeted drug and gene delivery and diagnostic imaging using quantum dots $[15,16]$, for the following reasons: (1) it is non-toxic, (2) its usefulness as a plasma expander, (3) its non-immunogenic properties, and (4) its non-antigenic properties. The pullulan modified magnetic nanoparticles reported previously in the literature were prepared by adding an aqueous solution of pullulan to magnetite particles dispersed in deoxygenated water [17]. In this method, the individual polymeric chains of pullulan need be cross-linked with glutaraldehyde. Pullulan modified magnetic nanoparticles can afford reduced cytotoxicity and enhanced cellular uptake [17]. However, the remaining glutaraldehyde may have an adverse effect on the human body. In this study, we describe a novel method to coat magnetic nanoparticles with pullulan acetate (PA) (Fig. 1(b)), a amphipathic derivative of pullulan. This method does not require

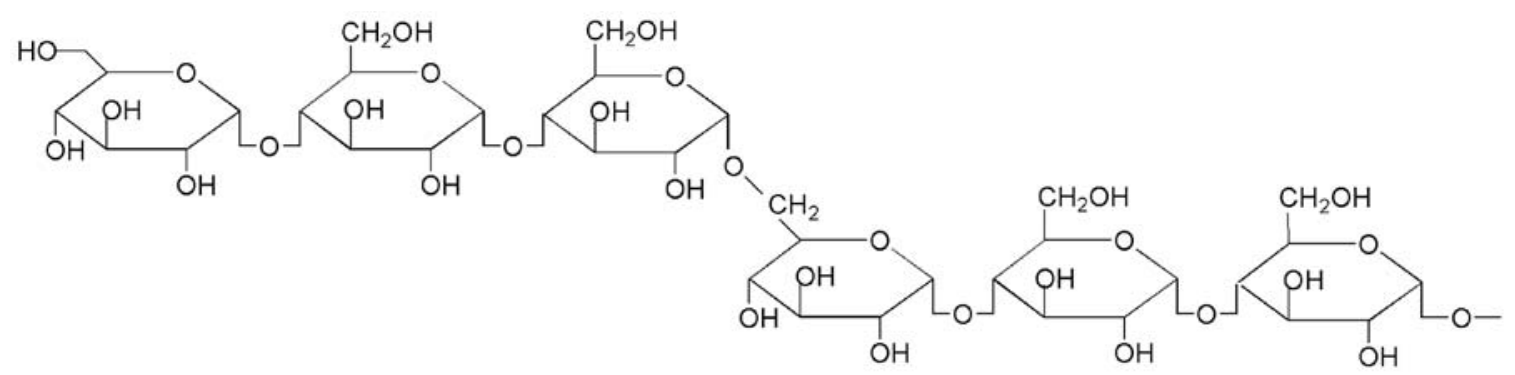

(a)

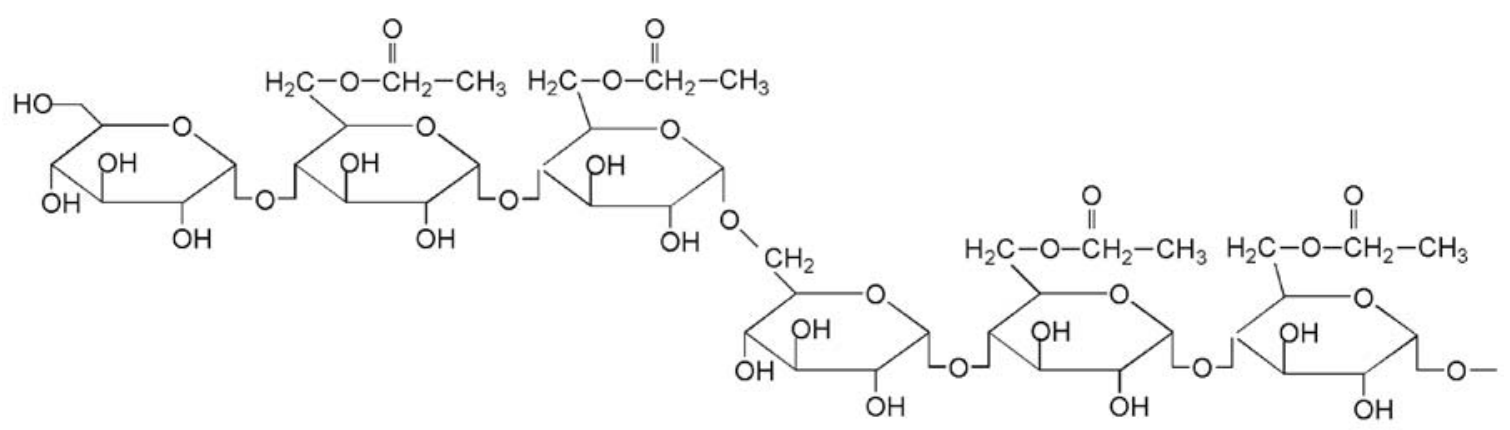

(b)

Figure 1 Chemical structure of pullulan (a) and PA (b) 
a cross-linking agent, and moreover is a rapid and easy process with a variety of ways to control the particle size.

The properties of the PA-coated magnetic nanoparticles (PAMNs), such as their morphology, particle size, and distribution, composition and magnetic properties were investigated by transmission electron microscopy (TEM), dynamic light scattering (DLS), thermogravimetric analysis (TGA), and vibrating sample magnetometry (VSM). Heating in vitro in an alternating magnetic field was carried out. The presence of the coating of PA on the magnetic nanoparticles was confirmed by Fourier transform infrared spectroscopy (FTIR). In vitro cytotoxicity of PAMNs was evaluated using L929 cells as model cells. Cellular uptake of nanoparticles, using KB cells as model cells, was visualized by TEM. The in vitro hyperthermic effect of PAMNs was examined using KB cells as model tumor cells. These results obtained will be useful for further application of the novel magnetic material in tumor thermotherapy.

\section{Experimental}

\subsection{Materials}

Pullulan $\left(M_{\mathrm{w}}=200000\right)$ was purchased from Hayashibara (Tokyo, Japan). Ferric chloride hexahydrate $\left(\mathrm{FeCl}_{3} \cdot 6 \mathrm{H}_{2} \mathrm{O},>99 \%\right)$, ferrous chloride tetrahydrate $\left(\mathrm{FeCl}_{2} \cdot 4 \mathrm{H}_{2} \mathrm{O}\right)$, ammonium hydroxide $\left(25 \mathrm{wt} \% \mathrm{NH}_{3}\right.$ in water), oleic acid $(90 \%)$, polyvinyl alcohol $\left(M_{\mathrm{w}}\right.$ 30 000-70 000), and 3-(4,5-dimethylthiazol-2-yl)-2,5diphenyltetrazolium bromide (MTT) were obtained from Sigma. All other reagents and solvents were analytical grade.

\subsection{Synthesis of PA and preparation of magnetite nanoparticles}

PA was synthesized following a literature method [18]. Magnetic $\mathrm{Fe}_{3} \mathrm{O}_{4}$ nanoparticles were prepared by controlled chemical co-precipitation of $\mathrm{Fe}^{2+}$ and $\mathrm{Fe}^{3+}$ (1:2 ratio) by a modification of the literature method [19]. In a typical experiment, $\mathrm{FeCl}_{3} \cdot 6 \mathrm{H}_{2} \mathrm{O}(11.6 \mathrm{~g})$ and $\mathrm{FeCl}_{2} \cdot 4 \mathrm{H}_{2} \mathrm{O}(4.30 \mathrm{~g})$ were dissolved in $400 \mathrm{~mL}$ of deionized water under nitrogen gas protection with vigorous stirring at $85^{\circ} \mathrm{C}$. Subsequently, about $20 \mathrm{~mL}$ of $25 \mathrm{wt} \%$ ammonia solution was added to the solution and stirring was continued for another $20 \mathrm{~min}$ to allow growth of the nanoparticles. The solution was then cooled to room temperature and the resulting particles were subjected to magnetic decantation followed by repeated washing with distilled water and ethanol. A portion of the resulting black precipitate was freeze-dried, and the remainder was redispersed in water and an excess of oleic acid $(4 \mathrm{~mL})$ was added dropwise into the suspension. The dark suspension was stirred for $1 \mathrm{~h}$ at $85^{\circ} \mathrm{C}$ under the protection of nitrogen gas. The resulting black magnetite gel was isolated by magnetic decantation. The magnetite gel was washed twice with sonication in acetone to remove excess oleic acid before dispersing in biopolymer solutions (see below).

\subsection{Preparation of PAMNs}

PAMNs were prepared by a solvent diffusion method. $50 \mathrm{mg}$ of wet magnetite gel and $100 \mathrm{mg}$ of PA were dissolved in separate $5 \mathrm{~mL}$ portions of dimethyl formamide (DMF). The two portions were mixed by vortex. The resulting solution was then added to an aqueous solution of $90 \mathrm{~mL}$ of poly(vinyl alcohol) (PVA) $(0.5 \%, w / w)$ by means of a syringe positioned with the needle directly in the medium, under moderate mechanical stirring. The magnetic particles were isolated by ultracentrifugation (Hitachi, CF 16RX) at $15000 \mathrm{rpm}$ for $20 \mathrm{~min}$ at $4{ }^{\circ} \mathrm{C}$ and washed three times with deionized water. The free PA was removed by magnetic separation of the magnetic particles which were subsequently freeze-dried for characterization.

\subsection{Characterization}

FTIR spectra of pullulan, $\mathrm{PA}$, naked $\mathrm{Fe}_{3} \mathrm{O}_{4}$ particles and PAMNs were recorded as $\mathrm{KBr}$ discs in the range $4000-400 \mathrm{~cm}^{-1}$ on a Nicolet 560 FTIR spectrometer. The average particle size, size distribution, and morphology of the magnetic nanoparticles were monitored using a Tecnai TF20 TEM. A drop of well-dispersed nanoparticles suspension was placed onto an amorphous carbon-coated 200 mesh copper grid, followed by drying the sample at ambient temperature, before it was loaded into the microscope. 
The mean size and size distribution of the naked $\mathrm{Fe}_{3} \mathrm{O}_{4}$ nanoparticles and PAMNs were measured by DLS (Malvern Mastersizer 2000) in phosphate buffered saline (PBS) ( $\mathrm{pH} 7.4$ ).

The content of $\mathrm{Fe}_{3} \mathrm{O}_{4}$ in the PAMNs was determined by TGA (Q5000 V3.5 Build 252). Samples weighing between 5 and $15 \mathrm{mg}$ were heated from 10 to $800{ }^{\circ} \mathrm{C}$ at a heating rate of $10{ }^{\circ} \mathrm{C} / \mathrm{min}$ in air. The magnetization of the nanoparticles was measured by VSM (DMA 1600).

Changes in temperature of the magnetic nanoparticles in an alternating magnetic field were observed using a heating system designed in Tsinghua University. The temperature was monitored using a copper-constantan thermocouple in an alternating magnetic field (frequency: $100 \mathrm{kHz}$, field intensity: $130 \mathrm{Gs})$.

\subsection{In vitro cell experiments}

\subsubsection{Cell cultures}

The cells cultivated for in vitro experiments were mouse fibroblast cell line, L929 cells, and human nasopharyngeal epidermal carcinoma cell line, KB cells. Cell obtained from the cell bank of Peking Union Medical College. All cell lines were cultured in RPMI Medium 1640 (Gibco) supplemented with 10\% fetal bovine serum (FBS; Gibco), 100 units/mL penicillin, and $100 \mu \mathrm{g} / \mathrm{mL}$ streptomycin at $37^{\circ} \mathrm{C}$ in a $5 \% \mathrm{CO}_{2}$ and $95 \%$ air humidified atmosphere.

\subsubsection{In vitro cytotoxity/viability studies}

To determine cell cytotoxicity/viability, L929 cells were seeded into 96-well tissue culture plates at a density of $1 \times 10^{4}$ cells/well at $37^{\circ} \mathrm{C}$ in a $5 \% \mathrm{CO}_{2}$ atmosphere. After $24 \mathrm{~h}$, the medium in the wells was replaced with fresh medium containing PAMNs at different concentrations (50, 100, and $200 \mu \mathrm{g} / \mathrm{mL}$ ). After $24 \mathrm{~h}$, the medium containing PAMNs was removed and the cells were washed three times with PBS to eliminate the remaining magnetic nanoparticles. $100 \mu \mathrm{L}$ of fresh culture medium and $20 \mu \mathrm{L}$ of MTT dye solution $(5 \mathrm{mg} / \mathrm{mL}$ in PBS $\mathrm{pH} 7.4$ ) were then added to each well. After incubation for $4 \mathrm{~h}$ at $37^{\circ} \mathrm{C}$ the medium was removed. Formazan crystals were extracted with
$200 \mu \mathrm{L}$ of dimethylsulphoxide (DMSO) and the solution was vigorously mixed to dissolve the reacted dye. After $10 \mathrm{~min}$, the absorbance of each well was read on a microplate reader (Bio-Rad 680) at $570 \mathrm{~nm}$. The spectrophotometer was calibrated to zero absorbance, using culture medium without cells. The relative cell viability (\%) relative to control wells containing cell culture medium without nanoparticles was calculated by the formula $[A]_{\text {test }} /[A]_{\text {control }} \times 100$, where $[A]_{\text {test }}$ is the absorbance of the test sample and $[A]_{\text {control }}$ is the absorbance of the control sample.

\subsubsection{TEM of cells exposed to PAMNs}

The KB cells were seeded in a 12-well plate at a concentration of $10^{6}$ cells $/ \mathrm{mL}$. Following incubation for $24 \mathrm{~h}$, PAMNs were introduced into the culture medium with an iron concentration of $0.1 \mathrm{mg} / \mathrm{mL}$. After $4 \mathrm{~h}$, the cells were washed three times with PBS, followed by careful detachment with a cell scraping knife. The cells were then centrifuged and fixed with $2.5 \%$ glutaraldehyde (Sigma) buffered in $0.2 \mathrm{~mol} / \mathrm{L}$ phosphate buffer (PB) for $1 \mathrm{~h}$ at $4{ }^{\circ} \mathrm{C}$. The cells were then post-fixed in $1 \%$ osmium tetroxide for $2 \mathrm{~h}$ at $4{ }^{\circ} \mathrm{C}$, washed again with PBS, dehydrated in an alcohol series, and embedded in Epon. Ultrathin sections of $70 \mathrm{~nm}$ thickness were examined by TEM at $50 \mathrm{kV}$.

\subsubsection{Hyperthermic therapy by exposure to an alternating magnetic field}

KB cells $\left(1 \times 10^{4}\right.$ cells/well $)$ were incubated in 96-well plates for $24 \mathrm{~h}$. The medium in the wells was replaced with the medium containing PAMNs $(200 \mu \mathrm{L})$. The cells were exposed to an alternating magnetic field (frequency: $100 \mathrm{kHz}$, field intensity: $130 \mathrm{Gs}$ ) for $20 \mathrm{~min}$. The temperature was adjusted to $45^{\circ} \mathrm{C}$ or $47^{\circ} \mathrm{C}$ according to the concentration of PAMNs. Then the medium containing PAMNs was removed and the cells were washed three times with PBS to eliminate the remaining magnetic nanoparticles. $200 \mu \mathrm{L}$ of fresh culture medium was then added to each well. After incubation for $24 \mathrm{~h}$ at $37{ }^{\circ} \mathrm{C}$, the cell viabilities were determined using MTT assay. The therapeutic efficacies were determined by calculating the differences between cell viabilities under treated and nontreated conditions. 


\subsubsection{Statistical analysis}

The statistical analysis of experimental data utilized the student's $t$-test and the results are presented as mean \pm standard deviations (S. D.). Statistical significance was accepted at a level of $p<0.05$.

\section{Results and discussion}

\subsection{Preparation and characterization of PAMNs}

To produce well-dispersed iron oxide colloidal solutions, we firstly prepared magnetic $\mathrm{Fe}_{3} \mathrm{O}_{4}$ nanoparticles modified with oleic acid, and the amphiphilic polymer PA was then coated onto the surfaces of the magnetic nanoparticles. The parent nanoparticles were synthesized by coprecipitation of ferrous and ferric ions in aqueous solution by addition of ammonium hydroxide.

Comparison of the FTIR spectra of pullulan (Fig. 2(a)) and PA (Fig. 2(b)) confirms the introduction of the acetate group in PA (Fig. 2(b)), as indicated by the $\mathrm{C}=\mathrm{O}$ stretch at $1750 \mathrm{~cm}^{-1}, \mathrm{CH}_{3}$ deformation at 1370 $\mathrm{cm}^{-1}$, and $\mathrm{O}-\mathrm{C}=\mathrm{O}$ bend at $602 \mathrm{~cm}^{-1}$. The absorption peak at $3470 \mathrm{~cm}^{-1}$ arising from the stretching vibration of the hydroxyl group is weaker in the spectrum of PA compared to that in pullulan. For the naked $\mathrm{Fe}_{3} \mathrm{O}_{4}$ (Fig. 2(c)), the peak at $577 \mathrm{~cm}^{-1}$ can be attributed to the $\mathrm{Fe}-\mathrm{O}$ groups. Comparing the FTIR spectra of naked $\mathrm{Fe}_{3} \mathrm{O}_{4}$ (Fig. 2(c)) and that of PAMNs (Fig. 2(d)), the characteristic bands of PA appeared near $1750 \mathrm{~cm}^{-1}$ and $1370 \mathrm{~cm}^{-1}$ in the spectrum of the PAMNs, confirming that PA was coated on the surface of the nanoparticles.

The shape, size, and degree of uniformity of the naked $\mathrm{Fe}_{3} \mathrm{O}_{4}$ nanoparticles and PAMNs were observed by means of TEM. The TEM image of the naked $\mathrm{Fe}_{3} \mathrm{O}_{4}$ nanoparticles (Fig. 3(a)) shows that the naked $\mathrm{Fe}_{3} \mathrm{O}_{4}$ nanoparticles were cubic shaped with an approximate size of around $10 \mathrm{~nm}$ and the particles were strongly agglomerated. This is similar to other reports in the Refs. $[13,20]$. The PAMNs were nearly spherical in shape and well-separated, but there was no significant change in size resulting from the PA coating process, as shown in Fig. 3(b).

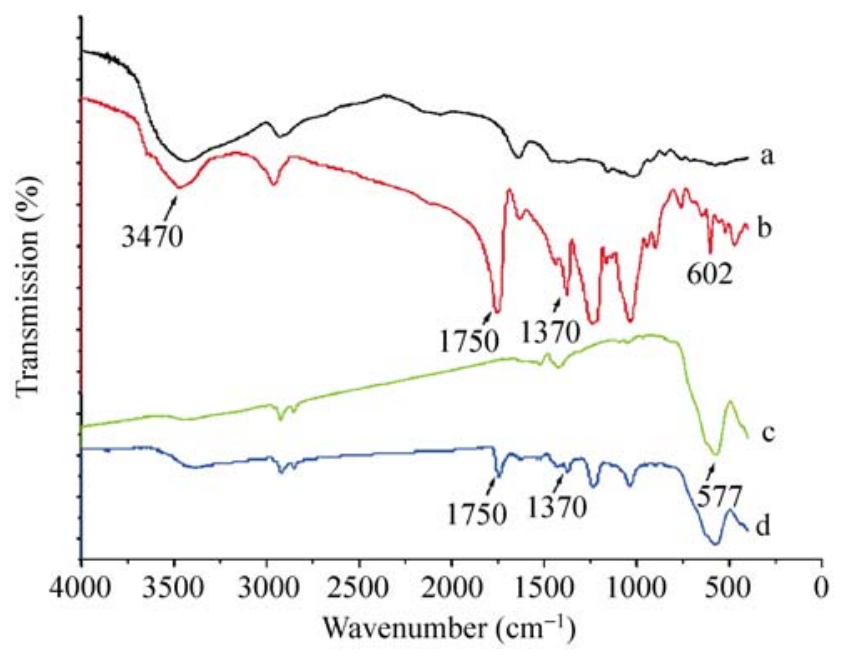

Figure 2 FTIR spectra of pullulan (a), PA (b), naked $\mathrm{Fe}_{3} \mathrm{O}_{4}$ particles (c), and PAMNs (d)
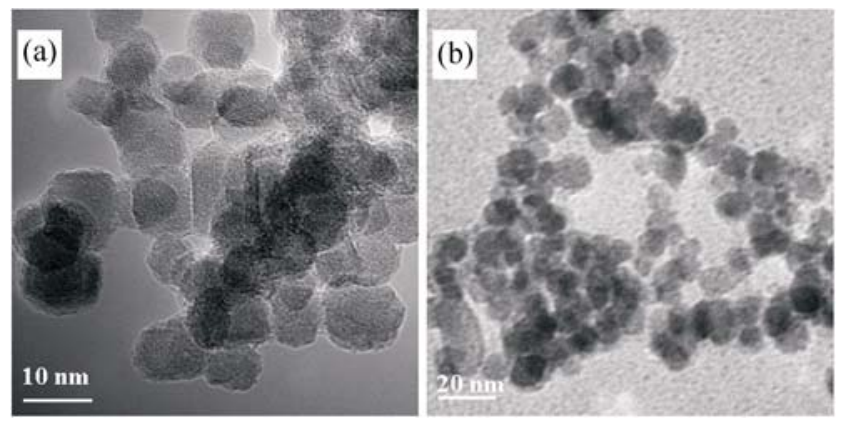

Figure 3 TEM images of naked $\mathrm{Fe}_{3} \mathrm{O}_{4}$ nanoparticles (a) and PAMNs (b)

Figure 4 shows the average size and size distribution of the naked $\mathrm{Fe}_{3} \mathrm{O}_{4}$ and PAMNs, as obtained by DLS. The size distribution of the naked $\mathrm{Fe}_{3} \mathrm{O}_{4}$ nanoparticles was bimodal, whilst that of PAMNs was unimodal. The average particle sizes were $70.8 \mathrm{~nm} \pm 4.4 \mathrm{~nm}$ and $25.8 \mathrm{~nm} \pm 6.1 \mathrm{~nm}$ for $\mathrm{Fe}_{3} \mathrm{O}_{4}$ nanoparticles and PAMNs, respectively. We believe that the bimodal size distribution of $\mathrm{Fe}_{3} \mathrm{O}_{4}$ nanoparticlescan be mainly attributed to particle aggregation. The average diameters obtained by DLS were larger than the sizes determined from the TEM images for the corresponding samples. This is presumably because DLS gives the mean hydrodynamic diameter of the magnetite core surrounded by the organic and solvation layers, whereas TEM gives the diameter of magnetic nanoparticles alone in the dry state [21-23]. 


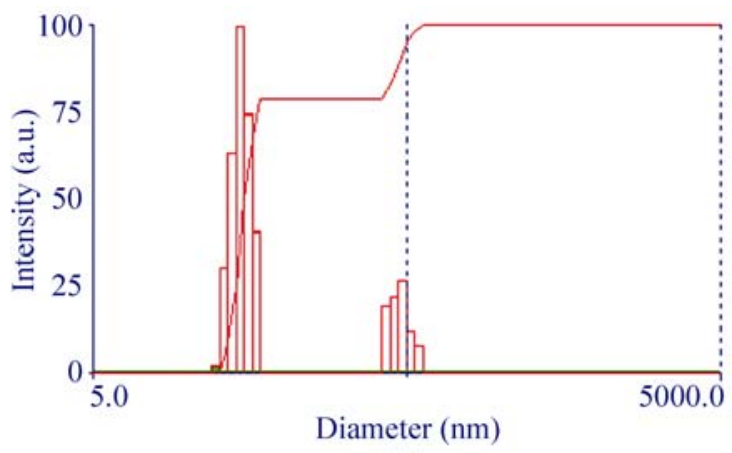

(a)

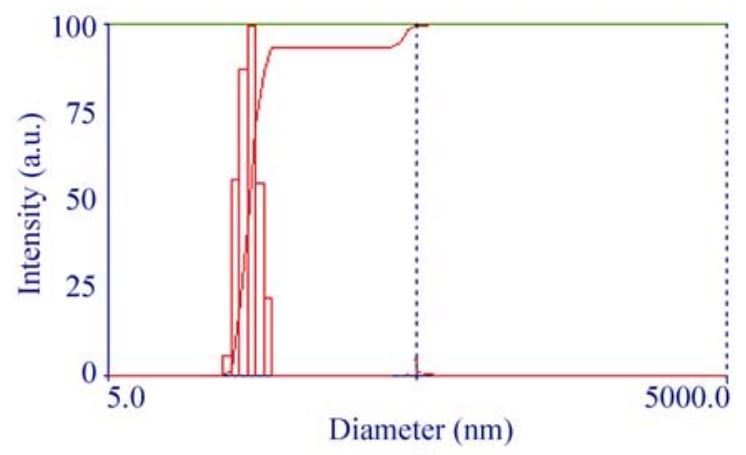

(b)

Figure 4 Particle size distributions of naked $\mathrm{Fe}_{3} \mathrm{O}_{4}$ particles (a) and PAMNs (b)

TGA was performed to confirm the coating formation and to estimate the content of $\mathrm{Fe}_{3} \mathrm{O}_{4}$ in the PAMNs. As shown in Fig. 5, the TGA curve shows that for the naked $\mathrm{Fe}_{3} \mathrm{O}_{4}$ particles the weight loss over the temperature range from 10 to $800{ }^{\circ} \mathrm{C}$ is about $2.5 \mathrm{wt} \%$. This might be due to the loss of residual water in the sample. In contrast, for the PAMNs a significant weight loss was observed above $200{ }^{\circ} \mathrm{C}$. This can be attributed to decomposition of the organic components of the coating. From the TGA curve, the content of the $\mathrm{Fe}_{3} \mathrm{O}_{4}$ particles in the PAMNs was estimated to be about $75 \mathrm{wt} \%$. This value was used below to estimate the net magnetization of the $\mathrm{Fe}_{3} \mathrm{O}_{4}$ particles in the PAMNs.

The superparamagnetic properties of magnetic nanoparticles are critical to ensure their application in the biomedical and bioengineering fields, since

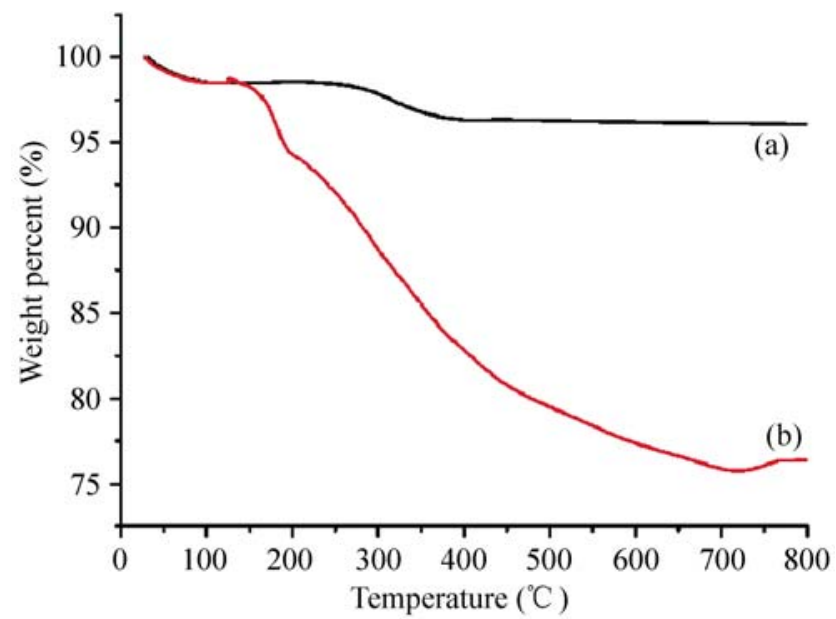

Figure 5 Thermogravimetric analysis (TGA) of naked $\mathrm{Fe}_{3} \mathrm{O}_{4}$ particles (a) and PAMNs (b) they prevent the particles from aggregating and enable them to redisperse rapidly as soon as the magnetic field is removed. To study the magnetic properties of the surface coated nanoparticles, magnetization measurements were performed using VSM. The magnetization curves for both the naked $\mathrm{Fe}_{3} \mathrm{O}_{4}$ nanoparticles and the PAMNs (Fig. 6) showed no hysteresis and were completely reversible at $300 \mathrm{~K}$. Neither coercivity nor remanence were observed, indicating the superparamagnetic nature of both materials. The saturation magnetization $\left(M_{\mathrm{S}}\right)$ of the naked $\mathrm{Fe}_{3} \mathrm{O}_{4}$ nanoparticles and the PAMNs was determined to be 68.8 and $51.9 \mathrm{emu} / \mathrm{g}$, respectively. The value for the PAMNs was lower than that of the naked nanoparticles due to the presence of the organic components. The $M_{\mathrm{S}}$ value expected for the PAMNs can be estimated on the basis of the TGA data via the

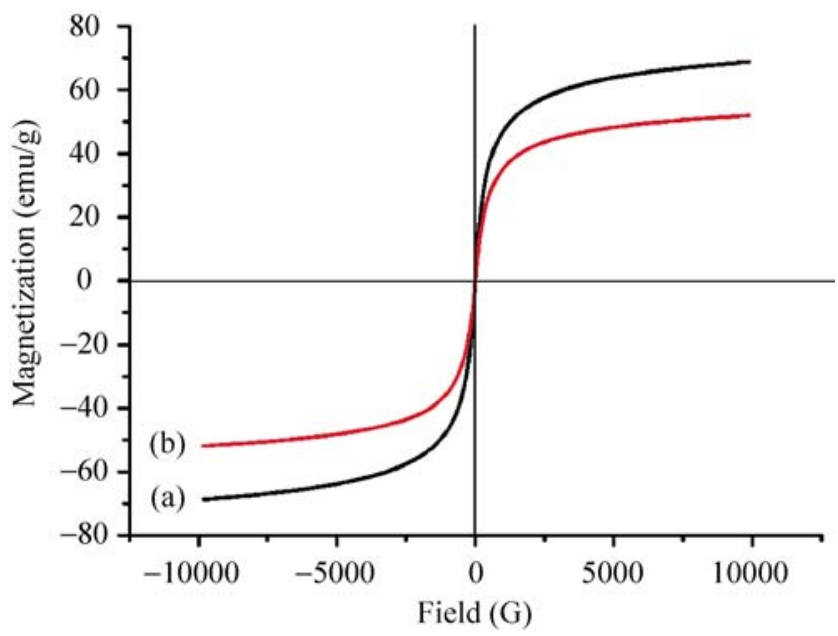

Figure 6 Magnetization curves for naked $\mathrm{Fe}_{3} \mathrm{O}_{4}$ particles (a) and PAMNs (b) at room temperature 
following formula:

$$
M_{\mathrm{S}}=M_{\mathrm{S}}^{\mathrm{Fe}_{3} \mathrm{O}_{4}}(1-\chi)
$$

where $M_{\mathrm{S}}^{\mathrm{Fe}_{3} \mathrm{O}_{4}}$ is the saturation magnetization of $\mathrm{Fe}_{3} \mathrm{O}_{4}$ nanoparticles $(68.8 \mathrm{emu} / \mathrm{g})$ and $\chi$ is the weight loss (wt $\%)$, determined by TGA. The $M_{S}$ value of PAMNs calculated via TGA correlates well with that determined by VSM. Moreover, the $M_{S}$ value of the PAMNs was higher than those for polymer-modified magnetites prepared by other methods [23, 24]. The higher magnetic content of our PAMNs ensured a better response of the nanoparticles towards an external magnetic field.

Figure 7 shows the changes in temperature of different concentrations of PAMNs in an alternating magnetic field. As the concentration of the magnetic particles increased, the temperature rise of the magnetic particles increased. The temperature of mixtures containing 20 and $40 \mathrm{mg} / \mathrm{mL}$ PAMNs in an alternating magnetic field reached $56^{\circ} \mathrm{C}$ and $85^{\circ} \mathrm{C}$, respectively, within $20 \mathrm{~min}$. The temperature change of the mixture with $40 \mathrm{mg} / \mathrm{mL}$ PAMNs was rapid, with the temperature reaching as high as $51^{\circ} \mathrm{C}$ within $1 \mathrm{~min}$. This rapid temperature change is advantageous for applications in hyperthermia. Magnetic particles in an alternating magnetic field must reach a temperature of $42-46{ }^{\circ} \mathrm{C}$ to be effective. As the time to reach this temperature gets longer, the normal tissues surrounding the tumor tissues sustain more damage from the magnetic field. Thus, shorter time periods are necessary for the preservation of normal tissues.

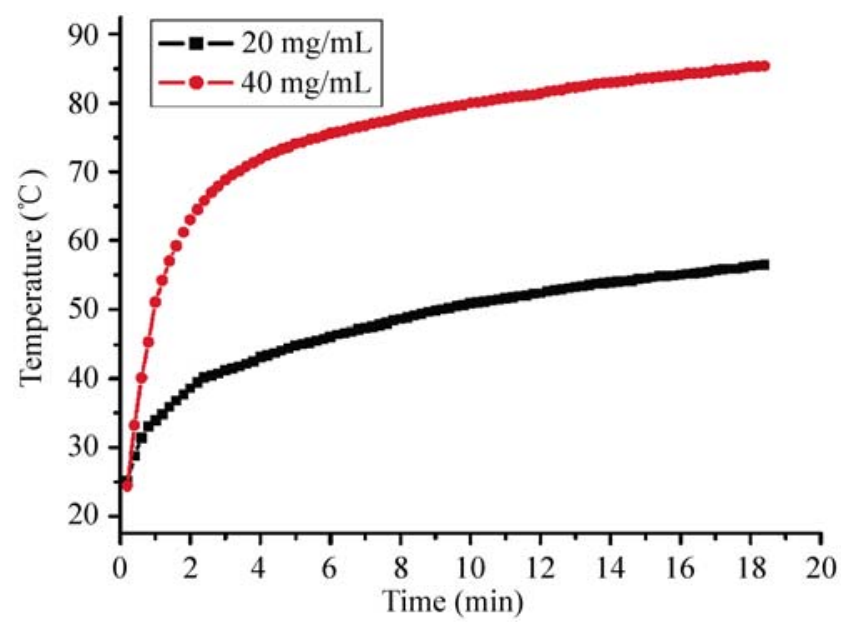

Figure 7 Temperature changes for different concentrations of PAMNs in an alternating magnetic field

\subsection{Cytotoxicity and cellular uptake of magnetic nanoparticles}

The MTT assay for cell viability evaluation has been described as a suitable method for detection of biomaterial toxicity [25]. MTT is a yellow, watersoluble tetrazolium salt. Metabolically active cells are able to convert this dye into a water-insoluble dark blue formazan by reductive cleavage of the tetrazolium ring. The formazan crystals can then be dissolved in an organic solvent such as DMSO and quantified by measuring the absorbance of the solution at $570 \mathrm{~nm}$; the resulting value is related to the number of living cells. As shown in Fig. 8, PAMNs showed no cytotoxic effects against L929 cells and they remained more than $90 \%$ viable relative to the control, even at concentrations of PAMNs as high as $0.2 \mathrm{mg} / \mathrm{mL}$. There was no significant difference between two groups in the cells viability.

Uptake of magnetic nanoparticles by tumor cells is essential for intracellular hyperthermia. To confirm that the PAMNs were indeed internalized by tumor cells and to visualize the location of the nanoparticles inside the cells after the internalization, TEM images were taken on KB cells that had been cultured with PAMNs (Fig. 9(b)) and compared with cells that had been cultured in the absence of PAMNs (Fig. 9(a)). This comparison shows that a large number of PAMNs accumulated in KB cells treated with PAMNs and appeared as black dots scattered in the cell cytoplasm. Some particles were also apparent on the cell surface. At higher magnification, it can be

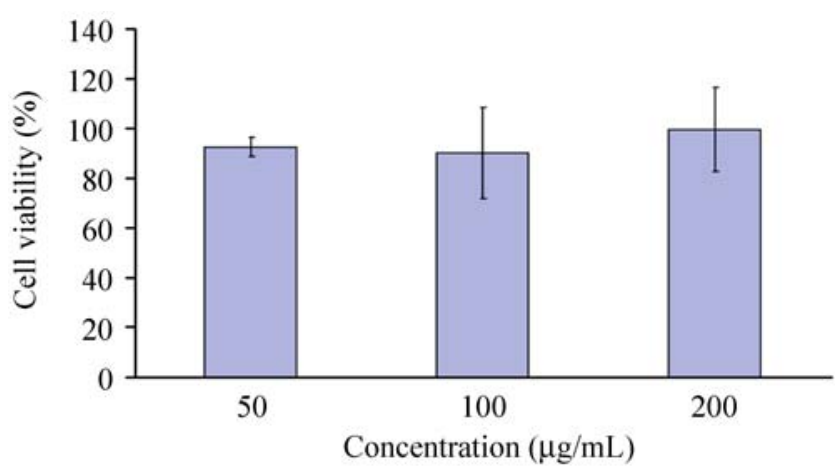

Figure 8 Cytotoxicity profiles of PAMNs when incubated with L929 cell lines, as determined by MTT assay. Percentage viability of L929 was expressed relative to control cells $(n=8)$. Results are represented as a mean with bars showing the S. D. 

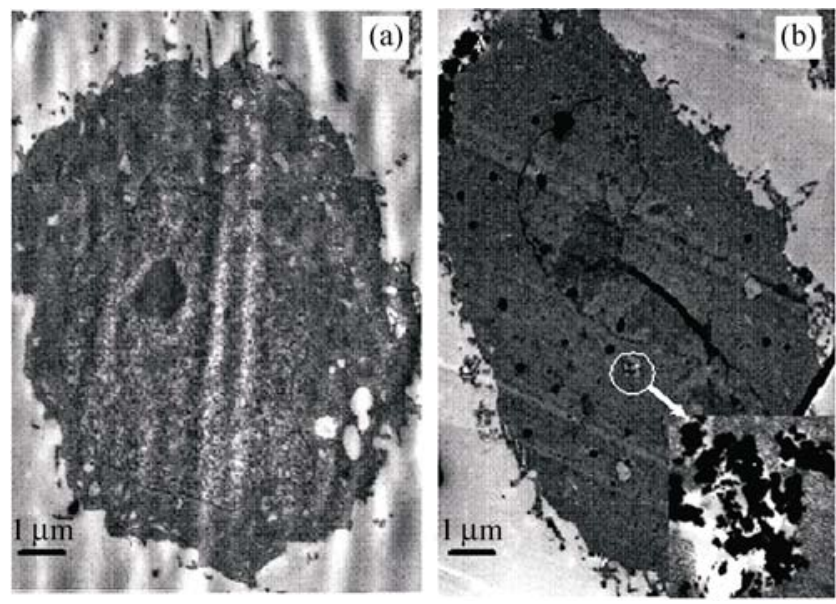

Figure 9 TEM images of $\mathrm{KB}$ cells (a) and $\mathrm{KB}$ cells cultured with PAMNs (b)

seen that the particles were located within a vesiclelike structure (inset of Fig. 9(b)), which is indicative of endocytosis of the particles.

\subsection{Hyperthermic effect of PAMNs on tumor cells}

We next determined the therapeutic potential of PAMNs as magnetic hyperthermic mediators with KB cells as a model cell by using the MTT assay. As shown in Fig. 10, we found that KB cells incubated with PAMNs in an alternating magnetic field showed therapeutic efficacies of about $56 \%$ and $78 \%$ at $45{ }^{\circ} \mathrm{C}$ and $47{ }^{\circ} \mathrm{C}$, respectively. The therapeutic efficacy was significantly different $(p<0.01)$ from that observed with a magnetic field alone.

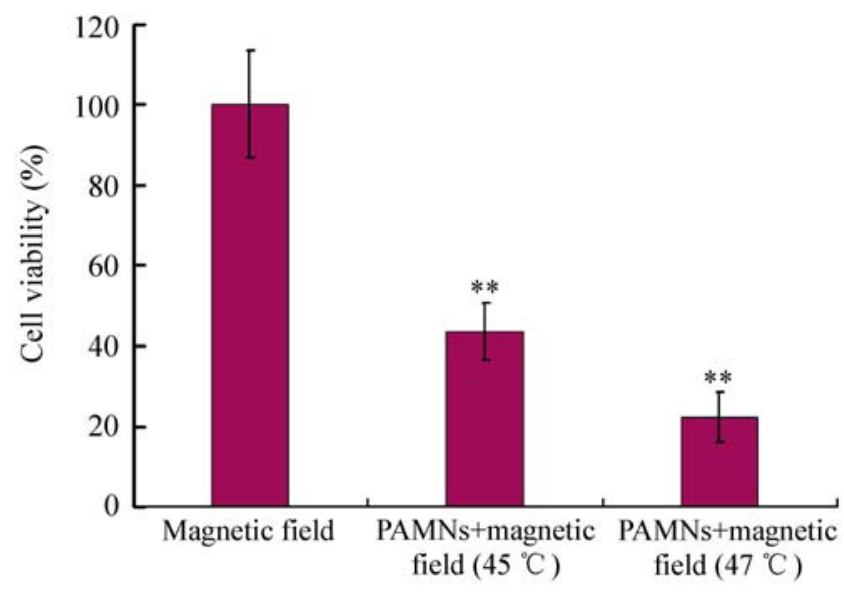

Figure 10 Hyperthermia efficacies of PAMNs on KB cells after exposure to an alternating magnetic field $\left({ }^{* *} p<0.01\right.$ compared with magnetic field alone)

\section{Conclusions}

A novel type of PAMNs has been fabricated by a solvent diffusion method. The magnetic nanoparticles were spherical in morphology with a unimodal size distribution. The mean diameter of the particles was $25.8 \mathrm{~nm} \pm 6.1 \mathrm{~nm}$. The saturated magnetization of the composite nanoparticles reached as high as $51.9 \mathrm{emu} / \mathrm{g}$ and the nanoparticles showed superparamagnetism. The magnetic PA-coated nanoparticles have high magnetite content and good biocompatibility. The composite nanoparticles have good heating properties in an alternating magnetic field and have evident cellular uptake by tumor cells. The PAMNs have an excellent therapeutic efficacy on KB cells stemming from the magnetic field induced hyperthermia. The new nanoparticles described here are very promising nanosystems for hyperthermic treatment of tumors.

\section{Acknowledgements}

This study was supported by the Beijing Municipal Science \& Technology Commission (No. Z07000200540704), the China Postdoctoral Science Foundation (No. 20090450417) and the Tsinghua Yuyuan Medical Fund.

\section{References}

[1] Islam, T.; Harisinghani, M. G. Overview of nanoparticle use in cancer imaging. Cancer Biomark. 2009, 5, 61-67.

[2] Jarrett, B. R.; Frendo, M.; Vogan, J.; Louie, A. Y. Sizecontrolled synthesis of dextran sulfate coated iron oxide nanoparticles for magnetic resonance imaging. Nanotechnology 2007, 18, 35603.

[3] Cho, S. J.; Jarrett, B. R.; Louie, A. Y.; Kauzlarich, S. M. Gold-coated iron nanoparticles: A novel magnetic resonance agent for T-1 and T-2 weighted imaging. Nanotechnology 2006, 17, 640-644.

[4] Park, J. Y.; Daksha, P.; Lee, G. H.; Woo, S.; Chang, Y. Highly water-dispersible PEG surface modified ultra small superparamagnetic iron oxide nanoparticles useful for target-specific biomedical applications. Nanotechnology 2008, 19, 365603.

[5] Chan, D. C. F.; Kirpotin, D.; Bunn, P. A. Synthesis and evaluation of colloidal magnetic iron-oxides for the 
site-specific radiofrequency induced hyperthermia of cancer. J. Magn. Magn. Mater. 1993, 122, 374-378.

[6] Park, J. H.; Im, K. Y.; Lee, S. H.; Kim, D. H.; Lee, D. Y.; Lee, Y. K.; Kim, K. M.; Kim, K. N. Preparation and characterization of magnetic chitosan particles for hyperthermia application. J. Magn. Magn. Mater. 2005, 293, 328-333.

[7] Kim, D. H.; Lee, S. H.; Im, K. H.; Kim, K. N.; Kim, K. M.; Shim, I. B.; Lee, M. H.; Lee, Y. K. Surface-modified magnetite nanoparticles for hyperthermia: Preparation, characterization, and cytotoxicity studies. Curr. Appl. Phys. 2006, 6S1, e242-e246.

[8] Matsunaga, T.; Sato, R.; Kamiya, S.; Tanaka, T.; Takeyama, $\mathrm{H}$. Chemiluminescence enzyme immunoassay using proteinAbacterial magnetite complex. J. Magn. Magn. Mater. 1999, 194, 126-131.

[9] Lubbe, A. S.; Bergemann, C.; Huhnt, W.; Fricke, T.; Riess, H.; Brock, J. W.; Huhn, D. Preclinical experiences with magnetic drug targeting: Tolerance and efficacy. Cancer Res. 1996, 56, 4694-4701.

[10] van der Zee, J. Heating the patient: A promising approach? Ann. Oncol. 2002, 13, 1173-1184.

[11] Engin, K. Biological rationale and clinical experience with hyperthermia. Control. Clin. Trials 1996, 17, 316-342.

[12] Hildebrandt, B.; Wust, P.; Ahlers, O.; Dieing, A.; Sreenivasa, G.; Kerner, T.; Felix, R.; Riess, H. The cellular and molecular basis of hyperthermia. Crit. Rev. Oncol. Hematol. 2002, 43, 33-56.

[13] Chastellain, M.; Petri, A.; Hofmann, H. Particle size investigations of a multistep synthesis of PVA coated superparamagnetic nanoparticles. J. Colloid. Interf. Sci. 2004, 278, 353-360.

[14] Cannas, C.; Gatteschi, D.; Musinu, A.; Piccaluga, G.; Sangregorio, C. Structural and magnetic properties of $\mathrm{Fe}_{2} \mathrm{O}_{3}$ nanoparticles dispersed over a silica matrix. J. Phys. Chem. B 1998, 102, 7721-7726.

[15] Kanatani, I.; Ikai, T.; Okazaki, A.; Jo, J. I.; Yamamoto, M.; Imamura, M.; Kanematsu, A.; Yamamoto, S.; Ito, N.; Ogawa, O. et al. Efficient gene transfer by pullulan-spermine occurs through both clathrin- and raft/caveolae-dependent mechanisms. J. Control. Release 2006, 116, 75-82.
[16] Hasegawa, U.; Nomura, S. M.; Kaul, S. C.; Hirano, T.; Akiyoshi, K. Nanogel-quantum dot hybrid nanoparticles for live cell imaging. Biochem. Biophys. Res. Commun. 2005, 331, 917-921.

[17] Gupta, A. K.; Gupta, M. Cytotoxicity suppression and cellular uptake enhancement of surface modified magnetic nanoparticles. Biomaterials 2005, 26, 1565-1573.

[18] Park, K. H.; Song, H. C.; Na, K.; Bom, H. S.; Lee, K. H.; Kime, S.; Kang, D.; Lee, D. H. Ionic strength-sensitive pullulan acetate nanoparticles (PAN) for intratumoral administration of radioisotope: Ionic strength-dependent aggregation behavior and ${ }^{99 \mathrm{~m}}$ Technetium retention property. Colloids Surf. B: Biointerfaces 2007, 59, 16-23.

[19] Liu, X. Q.; Kaminski, M. D.; Guan, Y. P.; Chen, H. T.; Liu, H. Z.; Rosengart, A. J. Preparation and characterization of hydrophobic superparamagnetic magnetite gel. J. Magn. Magn. Mater. 2006, 306, 248-253.

[20] Lin, C. L.; Lee, C. F.; Chiu, W. Y. Preparation and properties of poly(acrylic acid) oligomer stabilized superparamagnetic ferrofluid. J. Colloid. Interf. Sci. 2005, 291, 411-420.

[21] Kamruzzaman Selim, K. M; Ha, Y. S; Kim, S. J.; Chang, Y.; Kim, T. J.; Lee, G. H.; Kang, I. K. Surface modification of magnetite nanoparticles using lactobionic acid and their interaction with hepatocytes. Biomaterials 2007, 28, 710-716.

[22] Yoo, M. K.; Kim, I. Y.; Kim, E. M.; Jeong, H. J.; Lee, C. M.; Jeong, Y. Y.; Akaike, T.; Cho, C. S. Superparamagnetic iron oxide nanoparticles coated with galactose-carrying polymer for hepatocyte targeting. J. Biomed. Biotechnol. 2007, 94740.

[23] Li, G. Y.; Huang, K. L.; Jiang, Y. R.; Ding, P.; Yang, D. L. Preparation and characterization of carboxyl functionalization of chitosan derivative magnetic nanoparticles. Biochem. Eng. J. 2008, 40, 408-414.

[24] Ma, Z. Y.; Guan, Y. P.; Liu, H. Z. Synthesis and characterization of micron-sized monodisperse superparamagnetic polymer particles with amino groups. J. Polym. Sci. Polym. Chem. 2005, 43, 3433-3439.

[25] Mosmann, T. Rapid colorimetric assay for cellular growth and survival: Application to proliferation and cytotoxic assay. J. Immunol. Methods 1993, 95, 55-63. 